\title{
Crossing the Sectoral Divide: Modern Environmental Law Tools for Addressing Conflicting Uses on the Seabed
}

\author{
Rosemary Rayfuse
}

The oceans are becoming increasingly crowded. They are the venue for a vast range of human activities including merchant shipping, fishing, seabed mining, construction of artificial islands, undersea cables and pipelines, production of renewable energy, marine scientific research, and military uses. However, this complex, multidimensional and multi-faceted environment also provides a whole range of ecosystem services for humans, ranging from climate modulation and $\mathrm{CO}_{2}$ absorption to provision of food stuffs and mineral resources. Because of the fluid nature of the ocean medium, activities on and under the seabed, such as seabed mining or cable laying, interact with the water column, while activities on or in the water column, such as bottomtrawling, may also interact with the seabed. In other words, all ocean uses interact with the marine environment. Thus, existing and emerging ocean uses can pose serious threats to the marine environment from, among other things, over-exploitation and pollution.

Seabed activities, in particular, pose complex threats due to the perturbation of marine biodiversity and the water column caused by construction, exploration or exploitation activities. Even apart from pollution emergencies such as that caused by the Deep-Water Horizon incident, seabed mining may destroy critical fish habitat or interfere with submarine cables. Bottom-trawling may interfere with submarine cables or destroy critical habitat for a range of sedentary species and other marine genetic resources. Exploitation of marine genetic resources may destroy critical marine biodiversity or interfere with ocean energy development and production. Increasingly, the varying demands on ocean space and resources are leading to conflict between both existing sectors such as shipping and fishing and between existing and emerging sectors including seabed mining, ecotourism and marine renewable energy. This increasing competition is also leading to increasing pressures on the marine environment. 
Despite the overarching regime established by the Law of the Sea Convention (LOSC), ${ }^{1}$ regulation of ocean activities is essentially a sectoral matter. In areas under national jurisdiction, where coastal states enjoy jurisdictional competence in respect of seabed uses, marine governance regimes have traditionally been largely characterised by high levels of sector-specific, uncoordinated institutional fragmentation. ${ }^{2}$ The situation is even more fraught in areas beyond national jurisdiction $(\mathrm{ABNJ})$ where sectoral fragmentation has been compounded by substantive inadequacy and regulatory ineffectiveness. ${ }^{3}$ While a complex array of treaty regimes exists, governance, regulatory and substantive gaps hinder the ability of these regimes to adequately address both existing and emerging threats to the marine environment. ${ }^{4}$ The potential for inter-sectoral conflict such as between shipping, fisheries, mineral exploration and exploitation, cable and pipeline operations and mining operations, only exacerbates the problem.

In recent years, consensus has emerged on the need to promote crosssectoral cooperation and coordination in order to avoid inter-sectoral conflicts and to achieve sustainable environmental outcomes for the oceans. A number of general principles have emerged which provide the foundation for the development of normative frameworks and management approaches. These, in turn, provide the framework for the development of new management approaches and tools, designed to address conflicting uses on the seabed and conserve and protect the marine environment, that better reflect the holistic, fluid nature of the ocean and its uses. This chapter begins with a discussion of these principles (Section 2) and the broad normative frameworks (Section 3) and management approaches (Section 4) that have emerged. It then turns to a discussion of the key tools that have been developed to assist environmental management of marine and seabed uses (Section 5) and an examination of emerging frameworks for cross-sectoral management aimed specifically at avoiding, minimising or resolving conflicting uses on the seabed, particularly in ABNJ (Sections 6 and 7). It ends with some brief concluding remarks (Section 8).

1 United Nations Convention on the Law of the Sea, 10 December 1982, 1833 UNTS 3.

2 RK Craig, 'Marine Biodiversity, Climate Change and Governance of the Oceans' (2012) 4 Diversity 224, 231.

3 R Rayfuse, 'Climate Change, Marine Biodiversity and International Law' in M Bowman, P Davies and E Goodwin (eds) Handbook on Biodiversity and Law 123, 125 (Edward Elgar, 2016).

4 K Gjerde, H Dottinga, S Hart, E Molenaar, R Rayfuse, R Warner, Regulatory and Governance Gaps in the International Regime for the Conservation and Sustainable Use of Marine Biodiversity in Areas Beyond National Jurisdiction, IUCN Marine Law and Policy Paper No 1 (IUCN Gland, 2008). 
A glance at any law of the sea textbook reveals a plethora of principles, some contested, some well accepted, that are applicable to ocean and seabed uses. In the context of addressing conflicting uses of the seabed for the purposes of protecting the marine environment, the basic principles articulated in the preamble of the LOSC include those of due regard for the sovereignty of all states, facilitation of international communication, promotion of peaceful uses, equitable and efficient utilization of marine resources, conservation of living marine resources, and protection and preservation of the marine environment. These principles play a valuable role in helping to understand and assess the operation and efficacy of the management approaches and tools that are examined in the following sections. They are therefore worthy of brief elaboration.

The principle of due regard reflects the notion of equality of states and the requirement that states refrain from any acts which might adversely affect the rights and duties of other states. This requirement evokes two principles relevant to determining issues of compatibility of uses: protection of life at sea, and the necessity to ensure that, to the greatest extent possible, activities co-exist rather than trump one another. It is envisaged that some accommodation or adjustments may be needed to the manner in which activities are carried out in order to ensure these principles are met. For example, navigation may be restricted temporarily in areas surrounding weapons tests or oil and gas installations, or permanently by the construction of deep-water ports. Where accommodation is not possible then states must refrain from activities that interfere with the exercise by other states of their rights under the law of the sea. ${ }^{5}$

The principle of facilitation of international communication is essentially a manifestation of the principle of the freedom of the seas and its corollary of exclusivity of flag state jurisdiction according to which no state may appropriate unto itself sovereignty over the high seas or interfere in any way with the vessels of another state. Of course, the LOSC itself allocates sovereignty and sovereign rights over ocean spaces to coastal states. However, while coastal states may exercise sovereignty over their territorial seas, this sovereignty is subject to the obligation to allow innocent passage to the vessels of other states. ${ }^{6}$ Even less interference with foreign shipping is permitted in the exclusive economic

5 M Nordquist, (ed) United Nations Convention on the Law of the Sea: A Commentary, vol III, 86 (Martinus Nijhoff: Dordrecht, 1995).

6 Losc Article 17. 
zone (EEZ) where the coastal state is required to permit freedom of navigation and other states have the right to lay cables and pipelines, albeit subject to the coastal state's rights in respect of the continental shelf, exploitation of natural resources and prevention, reduction and control of pollution, and subject to the consent of the coastal state to the delineation of the course for the laying of such cables and pipelines. ${ }^{7}$

The principle of peaceful purposes is generally taken to refer to military activities and includes the general international law prohibition, articulated in Article 2(4) of the Charter of the United Nations, on the threat or use of force against the territorial integrity or political independence of other states. ${ }^{8}$ Military activities, per se, are not prohibited, but are rather governed by other rules of international law outside the LOSC regime. ${ }^{9}$ However, articulation of the peaceful purposes principle in the Losc reflects the desire of the negotiators to ensure that activities such as marine scientific research and other seabed activities would be carried out exclusively for peaceful purposes. ${ }^{10}$

Equitable and efficient utilization of resources entitles all states to an equitable share of marine resources which are to be utilised in such a way as to avoid wastage. This does not mean that all states receive an equal share in any particular resource. This is clear for example, in the context of fisheries where the coastal state enjoys the sovereign right to exploit ${ }^{11}$ and can exclude other states from fishing in its waters. Where the principle has its true effect is in areas beyond national jurisdiction. In the high seas, the freedom of fishing applies equally to all states, although not all states will share equally in either the physical practise of, or the economic benefit from, the catch. An even more important manifestation of this principle is reflected in the designation in Part XI of the LOSC of the non-living resources of the deep seabed beyond national jurisdiction as the common heritage of mankind and the establishment of a supranational management regime administered by the International Seabed Authority (ISA). ${ }^{12}$

The principle of conservation of marine living resources embodies the need to sustainably manage marine living resources, which include fish, marine mammals and all living marine genetic resources, for both current and future

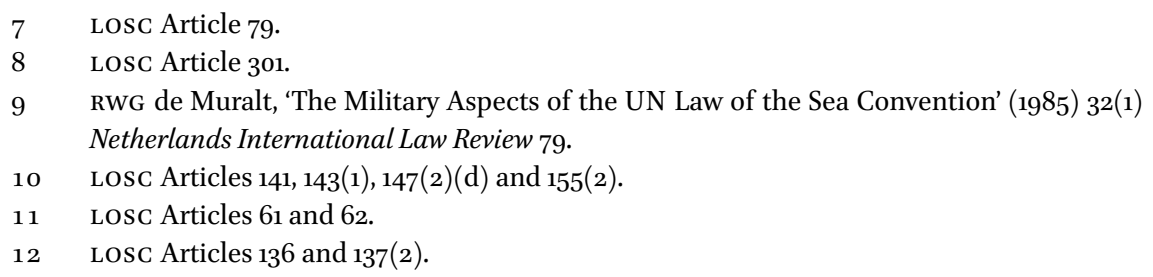


generations..$^{13}$ The principle is reflected in the duty on all states to take measures, both unilaterally and collectively, for the conservation of marine living resources. Importantly, the principle also encompasses effects not only on target species but on dependent and associated species as well. ${ }^{14}$ Thus it anticipates, at least in part, an ecosystem approach to the protection and preservation of the living elements of the world's oceans.

The principle of protection and preservation of the marine environment reflects the realisation of the importance of the oceans and their resources to human existence. This fundamental principle, embodied in Article 194 of the LOSC, imposes on all states the obligation to protect and preserve the marine environment from all sources of pollution, whether land, ship or air based, including the release of toxic, harmful or noxious substances, pollution from vessels, pollution from installations, intentional dumping, accidental discharges, and the introduction of alien species. Also required is the protection and preservation of rare or fragile ecosystems as well as the habitat of depleted, threatened or endangered species and other forms of marine life. This principle of environmental protection applies in respect of all ocean related activities, irrespective of where they are carried out. Thus, the principles above must also be read in light of this principle. The question is, however, how to operationalise the principle of protection and preservation of the marine environment, particularly in light of the multiplicity and variety of ocean uses.

\section{The Normative Frameworks for Environmental Approaches} to Oceans Management

Management of the oceans in a manner capable of protecting and preserving the marine environment is a complicated matter due to their dynamic spatial and temporal nature. In the context of environmental protection, two overarching approaches to the management of ocean activities have emerged: the precautionary approach and the ecosystem approach.

\subsection{The Precautionary Approach}

The precautionary approach - also referred to as the precautionary principle is of relatively recent vintage. Post-dating the LOSC, the essential core of the

\footnotetext{
13 R Rayfuse, 'Article 119 - Conservation of the Living Resources of the High Seas' in A. Proelss (ed), United Nations Convention on the Law of the Sea (UNCLOS): Commentary 830-850 (Verlag CH Beck, 2017).

14 LosC Article 119.
} 
precautionary principle as articulated in Principle 15 of the Rio Declaration ${ }^{15}$ is that in cases of possible serious or irreversible damage, lack of full scientific certainty shall not be used as a reason for postponing cost-effective measures to prevent environmental degradation. In such cases states are to apply the precautionary approach. ${ }^{16}$ The approach thus aims to guide decision making while recognising the existence of sometimes radical uncertainty and ambiguous and contestable scientific knowledge.

Neither the application nor the effect of the precautionary approach is free from controversy. For some, the approach provides the basis for early action to address threatening environmental issues. For others, the application of a precautionary approach is said to result in over-regulation and unwarranted limitations on human activity. Conflicting interpretations of the approach range from the requirement merely to act carefully when taking decisions that may have an adverse impact on the environment, to the requirement to regulate and possibly even prohibit activities and substances which may be environmentally harmful even in the absence of conclusive proof of such likely harm, to the requirement that the person wishing to carry out a particular activity must affirmatively prove it will not cause environmental harm. ${ }^{17}$ This latter interpretation, in particular, requires polluters to establish that their activities will not adversely affect the environment before they can be authorized to undertake the proposed activity, thus raising the connection between precaution and the requirements of environmental impact assessment (see section 5.1 below).

The precautionary approach is now required in an increasing number of environmental treaties, particularly treaties relating to the protection of the marine environment and the conservation and management of marine living resources. It is a key requirement in the 1995 United Nations Fish Stocks Agreement (FSA), ${ }^{18}$ and is now widely adopted in fisheries management regimes at both the national and the international level. In the seabed mining context, the precautionary approach lies at the heart of the development by

15 Rio Declaration on Environment and Development, 13 June 1992, UN Doc. A/ CONF.151/26; (1992) 31 International Legal Materials 874.

16 For comprehensive examinations of the precautionary principle in international law see, e.g., D Freestone, The Precautionary Principle: The Challenge of Implementation (Kluwer Law International, 1996) and A Trouwborst, Evolution and Status of the Precautionary Principle in International Law (Kluwer Law International, 2002).

17 P Sands and J Peel, Principles of International Environmental Law (3rd), (Cambridge University Press, 2012) 220.

18 Agreement for the Implementation of the Provisions of the United Nations Convention on the Law of the Sea of 10 December 1982, Relating to the Conservation and Management of Straddling Fish Stocks and Highly Migratory Fish Stocks, 4 August 1995, 2167 UNTS 3. 
the International Seabed Authority (ISA) of the its Mining Code ${ }^{19}$ and it has been recognised as a necessary element of the due diligence of states in regulating and conducting deep seabed mining. ${ }^{20}$

Given its wide acceptance in international and national law, it is generally accepted that the precautionary approach is trending towards becoming part of customary international law. ${ }^{21}$ While opinion may still be divided as to its precise scope, meaning and effect, there can be no doubt as to its central importance to the law of the sea and the protection and preservation of the marine environment. The question is simply how to operationalise it. In this respect, it is important to note that the precautionary approach does not prevent activities with unknown effects from proceeding. Rather, it merely requires that if they do proceed they must do so with caution, with awareness of unknown potential impacts, and with appropriate checks and risk-minimizing controls in place. Precaution also involves seeking out and evaluating alternatives to the proposed action, including the possibility of taking no action. Thus, decisions as to the measures to be taken cannot appeal solely to scientific or technical justifications but must also align with social and cultural values about what harm may - or may not - be considered acceptable. ${ }^{22}$ In other words, the concrete operationalisation of precaution is ultimately a task not only for law but also for the political realm. This is particularly relevant in the context of managing potentially conflicting seabed uses.

\subsection{The Ecosystem Approach}

Like the precautionary approach, the ecosystem approach is of relatively recent origin, having developed in response to recognition of a crisis in biodiversity conservation and the realisation of the inadequacies of single species

19 A Jaeckel, The International Seabed Authority and the Precautionary Principle, Brill 2017. See, as well, Chapter 8 in this book, H. Jessen, 'Advancing the Deep Seabed "Mining Code": Key Environmental Elements of the Regulatory Framework for the Commercial Exploitation of Mineral Resources'. The 'Mining Code' refers collectively to the rules, regulations and procedures adopted by the ISA regulations to regulate prospecting, exploration and exploitation of marine minerals in the international seabed area.

20 ITLos, Seabed Disputes Chamber, Responsibilities and Obligations of States Sponsoring Persons and Entities with Respect to Activities in the Area, Case No. 17, Advisory Opinion of 1 February 2011, https://www.itlos.org/fileadmin/itlos/documents/cases/ case_no_17/17_adv_op_010211_en.pdf.

21 Ibid, para. 135.

22 Rayfuse, 'Precaution and Climate Change: What Role for the Precautionary Principle in Addressing Global Warming' in T Hebeler, E Hoffmenn, A Proelss and P Reiff (eds) Protecting the Environment for Future Generations 61-78, 65 (Erich Schmidt Verlag, 2017). 
management. ${ }^{23}$ A seemingly intuitive approach, it recognises that the management and regulation of human activities that affect species, ecosystems and natural processes must be based on scientific knowledge of the wider systems in which such species, ecosystems or processes are situated, and that management measures must be designed and continuously adapted with consideration to the scales and dynamics (including the lack of full understanding) of ecosystem characteristics.

The scientific ideas on which the ecosystem approach is premised can be traced to the first half of the 2oth century and elements of it can be discerned in the LOSC provisions requiring protection of species dependent on and related to targeted fish stocks, ${ }^{24}$ protection and preservation of rare or fragile ecosystems and the habitat of depleted, threatened or endangered species and other forms of marine life in the pollution context. ${ }^{25}$ The ideas underlying the approach can also be traced to the requirements to regulate for the prevention of interference with the ecological balance of the marine environment and of damage to its flora and fauna in the deep seabed mining context. ${ }^{26}$

While the ecosystem approach famously forms the core objective of the 1982 Convention on the Conservation of Antarctic Marine Living Resources, ${ }^{27}$ it only gained general recognition in 1995 when the parties to the Convention of Biological Diversity (CBD $)^{28}$ adopted a 'common understanding' of the approach and called on all governments and international organisations to apply it. ${ }^{29}$ According to the 'common understanding' the ecosystem approach 'is a strategy for the integrated management of land, water and living resources that promotes conservation and sustainable use in an equitable way .... It 'requires adaptive management to deal with the complex and dynamic nature

23 RE Grumbine, 'What is ecosystem management' (1994) 8(1) Conservation Biology 27-38; KK Arkema, SC Abramson, BM Dewsbury, 'Marine ecosystem-based management: from characterisation to implementation' (2006) 4(10) Frontiers in Ecological Environment 525-532.

24 LOSC Articles 61(4) and 119(1)(b).

25 LOsC Article 194(5).

26 LOSC Article 145.

$27 \quad 9$ ATS 1982.

$28 \quad 1760$ UnTS 79.

29 On earlier expressions of the ecosystem approach or 'ecosystems thinking' in international law and policy, see A Trouwborst, 'The Precautionary Principle and the Ecosystem Approach in International Law: Differences, Similarities and Linkages' 18: 1 RECIEL (2009) 26-37, at pp. 27-30. 
of ecosystems and the absence of complete knowledge or understanding of their functioning. ${ }^{30}$

The ecosystem approach has come to feature particularly strongly in the context of ocean management, having been endorsed, inter alia, by the parties to the Helsinki and OSPAR Conventions relating to the protection of the marine environment of the Baltic Sea and North East Atlantic, respectively ${ }^{31}$ and, at the global level, in the $\mathrm{FSA}^{32}$ and in the emerging requirements of the ISA's Mining Code. An ecosystem-based approach is also increasingly found in national law and policy relating to environmental and natural resource use and conservation. Nevertheless, despite its acceptance, in principle, there exist a wide variety of definitions of the ecosystem approach and an even larger number of opinions as to the way in which it can be implemented or operationalized.

Given the various, and varying, features and complexities of both ecosystems and the legal/administrative systems governing them, effective implementation of the ecosystem approach can be highly challenging and requires consideration of a vast number of interconnected - and inter-disciplinary issues. This makes it difficult to articulate universally applicable rules for its effective operationalisation. Despite these challenges, however, the approach is now well established as a guiding principle (even if not necessarily a legal principle) in many contexts and its application is often seen as a prerequisite for the successful management of ecological systems (or rather the human activities affecting such systems). As with the precautionary approach, the question remains how to implement it.

\section{$4 \quad$ Management Approaches for Operationalizing Precaution and Ecosystem Management}

Implementing the precautionary and ecosystem approaches requires the development of management approaches capable of dealing with the ever-growing pressures on the marine environment from resource use and commercial activities. Increasingly, new approaches are being trialled. In the context of

30 UNEP/CBD, Fifth Meeting of the Conference of the Contracting Parties to the Convention on Biological Diversity (15-26 May 200o) Dec. V/6: Ecosystem Approach, U.N. Doc UNEP/ $\mathrm{CBD} / \mathrm{COP} / \mathrm{DEC} / \mathrm{V} / 6$ (16 May 200o).

31 Record of the First Joint Ministerial Meeting of the Helsinki and ospar Commissions (Bremen, 26 June 2003) (OSPAR/HELCom statement), Annex 5 ('Towards an Ecosystem Approach to the Management of Human Activities'). 
resource management, these include approaches such as co-management, adaptive management, adaptive co-management, active adaptive management and, most notably, ecosystem-based management.

Co-management refers to a collaborative approach whereby responsibility for resource management is shared between government and user groups. ${ }^{33}$ It is generally seen as an effective way of improving the legitimacy and efficiency of governance processes and management functions by decentralising resource management decisions, encouraging stakeholder participation and fostering dispute and conflict resolution. Inclusiveness in decision-making processes can both empower stakeholders and make them more accountable. It can also provide flexibility and the ability to adapt management regimes to new learned experiences. ${ }^{34}$ However, co-management can also lead to unreasonable and unfulfilled expectations regarding process and result, exacerbate existing power imbalances, and provide room for the hijacking of environmental protection concerns and non-use values by extractive interests or the vested interests of other user groups. ${ }^{35}$ In the absence of strong institutional structures it is generally considered that co-management arrangements can crumble under the weight of excessive and/or excessively diverse participation. ${ }^{36}$ Nevertheless, it does provide a platform for the resolution of disputes and the negotiation of trade-offs. ${ }^{37}$

Adaptive management refers to management by feedback loop whereby lessons learned from management decisions are fed back into the following rounds of decision-making. ${ }^{38}$ It ensures refinement and further development

33 S Sen, JR Nielsen, 'Fisheries co-management: a comparative analysis' (1996) 20 Marine Policy 405-418; S Singleton, 'Co-operation or capture? The paradox of co-management and community participation in natural resources management and environmental policy-making' (2000) 9(2) Environmental Policy 1-21.

34 E Pinkerton (ed) Co-operative Management of Local Fisheries: New Directions for Improved Management and Community Development (UBC Press, 1989); JR Nielsen, P Degnbol, KK Viswanathan, M Ahmed, M Hara, NMR Abdullah, 'Fisheries comanagement and institutional innovation? Lessons from South East Asia and Southern Africa' (2000) 28(2) Marine Policy 151-160.

35 S Singleton, 'Co-operation or capture? The paradox of co-management and community participation in natural resource management and environmental policy-making' (2000) 9(2) Environmental Politics 1-21.

36 M Haward, 'Outstanding issues with regimes for ocean governance' in D Wilson and R. Sherwood (eds) Oceans Governance and Maritime Strategy 121-128 (Allen and Unwin, 2000).

37 L Carlsson and F Berkes, 'Co-management: concepts and methodological implications' (2005) 75 Journal of Environmental Management 65-76.

38 CR Allen, JJ Fontaine, J Pope, AS Garmestani, 'Adaptive management for a turbulent future' (2011) 92 Journal of Environmental Management 1339-1345. 
as experience and knowledge increase. Adaptive management is said to address the challenge of operating with either impartial or incomplete knowledge thereby allowing progress in the absence of complete information. ${ }^{39}$ In this respect, it can be seen as a manifestation of the precautionary approach. Importantly, it attempts to account for complexity by considering multiple sectors and policies, ${ }^{40}$ thereby embracing complexity, variability and uncertainty. However, while theoretically an iterative process that can reduce uncertainty and deal with change through management of short and long-term impacts, the danger exists for passivity to replace learning and adaptation thereby pushing the system to a threshold at which abrupt, and unwelcome, change occurs. ${ }^{41}$

Active adaptive management and adaptive co-management are more responsive or highly developed versions of their namesakes. Active adaptive management is an iterative process of experimentation and re-experimentation designed to test hypotheses through the use of ecosystem scale holistic management experiments. However, this continued hypothesis-generation and testing can significantly impact the security and stability of the operating environment for both commercial operators and management authorities. ${ }^{42}$ Nevertheless, this approach to management embraces ecosystem scale and system complexity in both human and ecological terms. ${ }^{43}$ Adaptive comanagement, for its part, links adaptive management with co-management and ecosystem dynamics. Seen as a means of studying or structuring increasingly coupled social and ecological systems it is considered more suited to developing adaptive capacity, social-ecological resilience, sustainable resource use and enhanced efficiency and effectiveness of management. ${ }^{44}$ Its success

39 E Ogier, J Davidson, P Fidelman, M Haward, AJ Hobday, NJ Holbrook, E Hoshino and GT Peci, 'Fisheries management approaches as platforms for climate change adaptation: Comparing theory and practice in Australian fisheries' (2016) 71 Marine Policy 82-93, 86.

$40 \quad$ F Berkes, Implementing ecosystem-based management: evolution or revolution? (2012) 13 Fish and Fisheries $465-476$.

41 J McDonald, MC Styles 'Legal strategies for adaptive management under climate change' (2014) 26(10) Journal of Environmental Law 25-53.

42 C Allen and A Curtis, 'Nipped in the bud: why regional scale adaptive management is not blooming' (2005) 36(3) Environmental Management 414-425.

43 Ogier et al, $\mathrm{n} 39$.

44 P Olsen, C Folke and F Berkes, 'Adaptive co-management for building resilience in socialecological systems' (2004) 34(1) Environmental Management 75-90. 
is, however, highly dependent on the quality of decision-making and communication processes and on high levels of engagement by industry or other relevant stakeholders. ${ }^{45}$

The final management approach to be mentioned is that of ecosystembased management which, as its names implies, is generally considered to be the most effective way of implementing the ecosystem approach because of its explicit consideration of all aspects of the main extrinsic forcers on ecosystem dynamics and their impacts on both human and non-human species and the environments in which they live. ${ }^{46}$ Ecosystem-based management recognises the needs of an ecosystem as a whole, as opposed to those pertaining only to the particular target of management. In doing so it incorporates consideration of non-target dependent and related species as well as habitats and ecological communities and aims to sustain a broader range of ecosystem services. It also aims to integrate decision-making relating to all human activities that affect a particular ecosystem. In theory, by maximising ecosystem resources and services, it makes for their more efficient and sustainable use. As Warner puts it, ecosystem-based management has added 'a new dimension to marine environmental protection which has previously focused on prevention and control of marine pollution and the protection of single species'. ${ }^{47}$ However, implementing ecosystem-based management is notoriously difficult, not least because of its complex data requirements, potentially prohibitive monitoring costs, and a general lack of scientific knowledge of ecosystem dynamics and/or their responses to human interventions. Robust precautionary environmental management tools are therefore required to support its implementation.

\section{5 \\ Modern Environmental Management Tools That Support Precautionary Ecosystem-Based Management}

Key tools that have been developed to support precautionary ecosystem-based management include environmental impact assessments (EIAS) and areabased management tools, such as marine protected areas (MPAS).

45 F Berkes, 'Evolution of co-management: the role of knowledge generation, bridging organisational and social learning (2009) 9o(5) Journal of Environmental Management 1692-1702; GP Kofinas, 'Adaptive co-management in Social-Ecological Governance, in FS Chapin III, GP Kofinas, C Folke (eds) Principles of Ecosystem Stewardship: Resilience Based Natural Resources Management in a Changing World, (Springer New York, 2009) 77-101.

46 Ogier et al, $\mathrm{n} 39$.

47 R Warner, 'Conserving marine biodiversity in the global marine commons: co-evolution and interaction with the Law of the Sea' (2014) 1(6) Frontiers in Marine Science 1-23, 5. 


\subsection{Environmental Impact Assessment}

EIA is generally defined as 'a process of evaluating the likely environmental impacts of a proposed project or development taking into account interrelated socio-economic, cultural and human health impacts, both beneficial and adverse. ${ }^{48}$ EIAs are particularly useful for determining and analysing the likely environmental impacts of human activities, developing mitigation measures, and identifying activities that should not be authorised to proceed because the impacts will either be too severe or too uncertain. Acknowledged in Principle 17 of the Rio Declaration ${ }^{49}$ as a key element in the suite of tools for environmental protection, EIAs are a well-established practice in the domestic realm. The obligation to undertake EIAs in the transboundary context is also well recognised in international law. ${ }^{50}$

In $\mathrm{ABNJ}$, however, the requirement to carry out EIAs is less well defined. Article 206 of the LOSC requires states to carry out environmental assessments 'when States have reasonable grounds for believing that planned activities under their jurisdiction or control may cause substantial pollution or significant and harmful changes to the marine environment'. This includes activities in $\mathrm{ABNJ}$. However, the obligation itself is neither well-defined nor universally implemented. ${ }^{51}$ While the general obligation has been made more specific in some other global agreements and in some sector specific and regional agreements, there remain significant gaps with respect to a number of activities that have the potential to cause significant impacts to the marine environment, including seabed activities other than seabed mining. ${ }^{52}$

With respect to seabed activities in $\mathrm{ABNJ}$, no specific EIA requirements exist in relation to the laying of cables and pipelines, construction and operation of seabed installations, the conduct of marine scientific research, bioprospecting and sea-based tourism. Only in the contexts of deep seabed mining and bottomfishing have detailed EIA requirements begun to emerge. With respect to the former, assessments of the environmental impacts of activities in the Area are

48 Voluntary Guidelines on biodiversity-inclusive impact assessment. СвD соР 8 Decision VIII $/ 28$ on Impact Assessment, Annex, sec. 5 .

491992 Rio Declaration on Environment and Development, UN Doc. A/CONF.151/26, (1992) 31 ILM 874.

$5^{0}$ See, e.g., Convention on Environmental Impact Assessment in a Transboundary Context, 25 February 1991 (Espoo Convention); Pulp Mills on the River Uruguay (Argentina v Uruguay) Judgement, ICJ Reports 2010, para 204.

51 R Warner, 'Environmental assessment in marine areas beyond national jurisdiction' in R Rayfuse (ed), Research Handbook on International Marine Environmental Law (Edward Elgar, 2015) 291-312, 292.

52 E Druel, Environmental impact assessments in areas beyond national jurisdiction' Studies No 01/13 (IDDRI, Paris France, 2013). 
mandated by the provisions of Part XI of the LOSC and its 1994 Implementing Agreement and have now been recognised as an obligation under customary international law. ${ }^{53}$ Detailed regulations for the conduct of such assessments have been incorporated into the regulations relating to prospecting and exploration for deep seabed minerals adopted by the ISA as part of its Mining Code ${ }^{54}$ and are the subject of intense discussion in the ongoing discussions on the development, by the ISA, of its exploitation regulations. ${ }^{55}$ With respect to the latter, assessment of the adverse impacts of bottom fishing activities on vulnerable marine ecosystems is required by UN Resolution ${ }^{56}$ and detailed EIA requirements have been developed in the FAO International Guidelines for the Management of Deep-Sea Fisheries in the High Seas and adopted by a number of regional fisheries management organisations (RFMOs).

Even where detailed requirements have been adopted, considerable inconsistency exists between regions and across sectors. In addition, not all sectors have developed legally binding requirements on EIAS in ABNJ. Moreover, no requirement exists to assess the cumulative impacts of human activities in ABNJ or to conduct cross- or inter-sectoral assessments. ${ }^{57}$ The current negotiations on the possible development of an implementing agreement to the LOSC on marine biodiversity in ABNJ may result in the establishment of a default mechanism for the assessment and regulation of new and emerging activities as well as those not currently covered by EIA requirements and/or a standardised model for EIA requirements. As currently conceived, this would complement, rather than negate, the need for existing sectoral and regional EIA processes. ${ }^{58}$

\subsection{Area-Based Management Tools}

Area-based management tools have long been accepted in both the national and the international sphere. While there is no universally accepted definition of 'area-based management', it clearly refers to management on the basis of an area in which the regulation of human activity is more stringent than in the immediately surrounding area. A traditional single sector management approach, area-based measures include everything from areas closed to fishing

\footnotetext{
53 ITLOS, Advisory Opinion, n 20, para 145.

54 Nodules Regulations, reg 31(6), Sulphides and Crusts Regulations, reg 33(6).

55 A Jaeckel, The International Seabed Authority and the Precautionary Principle: Balancing Deep Seabed Mining and Marine Environmental Protection (Brill, Nijhoff, 2017) 230-251.

$56 \quad$ UNGA Resolution 61/105 of 8 December 2006.

57 Druel, $\mathrm{n}_{52}$.

$5^{8}$ Warner, n 51, 307.
} 
during spawning season to marine areas in which shipping or other human activities are regulated or restricted in some manner.

In $\mathrm{ABNJ}$, traditional area-based management tools are often used by RFMOs to close fisheries either to specified gear types, or for seasonal purposes, or once quotas have been reached. ${ }^{59}$ They are also manifest in the IMo's designations of Particularly Sensitive Sea Areas (PSSAs). In the seabed mining context in ABNJ, area-based measures are explicitly included in the ISA's Exploration Regulations which provide for the establishment of both preservation reference zones (PRZs) and impact reference zones (IRZs); the former consisting of pristine areas in which mining is not allowed, the latter consisting of areas in which mining takes place. ${ }^{60}$ The purpose of these zones is to facilitate assessment of the effects of mining on the marine environment. ${ }^{61} \mathrm{~A}$ more comprehensive area-based approach is taken in the Environmental Management Plan for the Clarion Clipperton Zone (EMP-CCZ), adopted by the ISA in $2012,{ }^{62}$ which sets out a spatial management plan for an area of deep seabed in the eastern central Pacific which is roughly equivalent in size to Europe. ${ }^{63}$ A central feature of the plan is the designation of nine Areas of Particular Environmental Interest (APEIS) in which mining activities are prohibited. The purpose of these areas is both to protect representative habitat and to facilitate marine scientific research, although questions have been raised as to their utility given the adjustments to size and location that were made prior to adoption of the EMP-CCZ to accommodate pre-existing mining leases. ${ }^{64}$ Nevertheless, the EMP-CCZ is generally considered a good example of both precautionary and ecosystem-based management. ${ }^{65}$

The tool that has received the most attention in recent years is that of marine protected areas (MPAs). Although similarly lacking a singular definition, MPAs include such things as marine sanctuaries, marine parks, wildlife refuges, fisheries closures, no-take MPAs, multiple use MPAs, marine reserves

59 R Rayfuse, 'Regional Fisheries Management Organisations' in D Rothwell, A Oude Elferink, K Scott and T Stephens, Oxford Handbook of the Law of the Sea 439-462 (Oxford University Press, 2015).

6o Nodules Regulations reg 31(6) and Sulphides and Crusts Regulations reg 33(6).

61 Jaeckel, $\mathrm{n}$ 55, 211-212.

62 ISA, ISBA/17/LTC/7 (13 July 2011), para 21.

63 M Lodge, et al, 'Seabed Mining: International Seabed Authority Environmental Management Plan for the Clarion-Clipperton Zone. A Partnership Approach' (2014) 49 Marne Policy $66-72,72$.

64 LM Wedding et al, 'Managing Mining of the Deep Seabed' (2105) 349 Science 144-145 and Jaeckel, n 55, 206.

65 M Lodge, 'Protecting the environment of the deep seabed' in R Rayfuse (ed), Research Handbook on International Marine Environmental Law (Edward Elgar, 2015), 151-169, 167. 
and ecological reserves. Clearly, the ISA's PRZs and APEIs can also be seen as a form of protected area or MPA. However, it must be remembered that the ISA can only regulate activities relating to deep seabed mining and not other activities in these areas. They are thus not multi-sector MPAs.

The use of multi-sector MPAs as a management tool is increasingly seen as a central element of ecosystem-based management. In 2002 the World Summit on Sustainable Development called for the use of diverse approaches and tools to protect marine biodiversity including though the establishment of representative networks of MPAs by 2012. ${ }^{66}$ The Aichi Biodiversity Targets, adopted by the parties to the CBD in 2010, call for 10 percent of coastal and marine areas to be conserved through MPAs by 2020, ${ }^{67}$ although it must be admitted that, at this stage, achievement of that goal seems unlikely. Recent assessments show only 5.1 percent of areas under national jurisdiction and 0.17 percent of the high seas as being protected by MPAs. ${ }^{68}$ While this latter number has increased with the adoption by the Commission on the Conservation of Antarctic Marine Living Resources of the Ross Sea MPA in 2016,69 the prospects of meeting the global 2020 target seem slim. This is in large part due to lingering uncertainties as to the rationale for and efficacy of these measures, many of which are designated in remote areas, ${ }^{70}$ lack management plans, allow many types of extractive activities, ${ }^{71}$ and are not enforced or monitored, ${ }^{72}$

66 Plan of Implementation of the World Summit on Sustainable Development, para 32(c).

67 This was originally to have been achieved by 2012 however it became clear that target would not be achieved so the deadline was extended to 2020. СвD 2010 Decision X/2 $\mathrm{UNEP} / \mathrm{CBD} / \mathrm{COP} / 10 / 27$.

68 BH e Costa, J Claudet, G Franco, K Erzini, A Caro, EJ Gonçalvez, 'A regulation-based classification system for Marine Protected Areas (MPAs)' (2016) 72 Marine Policy 192-198, 192.

69 CCAMLR, Conservation Measure 91-05 (2016) 'Ross Sea region marine protected area', https://www.ccamlr.org/en/measure-91-05-2016.

70 PJS Jones and EM De Santo, 'Viewpoint - is the race for remote, very large marine protected areas (VLMPAs) taking us down the wrong track?' (2016) 73 Marine Policy 231-234.

71 MD Spalding, I Meliane, NJ Bennett, P Dearden, PG Patie and RD Brumbaugh, 'Building towards the marine conservation end-game: consolidating the role of MPAs in a future ocean' (2016) 26 (Suppl. 2) Aquatic Conservation: Marine and Freshwater Ecosystems 185-199.

72 R Devillers, RI Pressey, A Greech, JN Kittinger, GJ Edgar, T Ward, R Watson, 'Reinventing residual reserves in the sea: are we favouring ease of establishment over need for protection?' (2015) 25(4) Aquatic Conservation: Marine and Freshwater Ecosystems 48-504; P Leenhardt, B Cazalet, B Salvat, J Claudet, F. Feral, 'The rise of large-scale marine protected areas: conservation or geopolitics?' (2013) 85 Oceans and Coastal Management 112-118; J Lubochenko, K Grorud-Colvert 'Making waves; the science and politics of ocean protection (2015) 350(6259) Science 382-383; AN Rife, B Erisman, A Sanchez, O Aburto-Oropeza, 'When good intentions are not enough ... Insights on networks of 'paper parks' marine protected areas' (2013) 6(3) Conservation Letters 200-212. 
as well as to their potential knock-on effects of excluding stakeholders either from their livelihoods entirely or from participation in the development and/ or implementation of management measures. ${ }^{73}$

An additional complicating factor in the acceptability and efficacy of MPAs as a management tool arises where these are established on a sectoral basis thereby creating the potential for inter-sectoral conflict. This is relevant in the case of seabed uses where implementation and enforcement of an MPA designed to protect the water column (i.e. fisheries) may interfere with seabed uses (i.e., resource extraction, wind farms, shipping) and vice versa; or where a seabed MPA is adopted to protect from the adverse effects of seabed mining but not from other seabed uses such as cable laying, oil and gas extraction, wind farm construction or marine scientific research. Still greater levels of complication arise in the case of MPAS in ABNJ where no overarching management authority exists and individual treaty regimes are fragmented sectorally, substantively, geographically and in terms of participation. ${ }^{74}$ Questions thus persist as to how MPAs (and other area-based measures) can be brought under an integrated protection scheme both within a particular sector and beyond and, more importantly, how cooperation and coherence, or harmonisation, between competent management authorities can be shaped in order to cross the sectoral divide. ${ }^{75}$

When it comes to managing ocean uses, as noted above, traditional management structures have revolved around single sector or even, in the case of living resources, single species management. However, the dynamic nature of new and emerging ocean uses, particularly when coupled with the realisation of existing and emerging threats to the oceans from pollution, over-exploitation, habitat destruction, climate change and ocean acidification, call into question the effectiveness and flexibility of traditional, sectoral management approaches. In areas under national jurisdiction this has led to the development of new management approaches that cross the sectoral divide in order

73 SC Gall and LD Rodwell, 'Evaluating the social acceptability of Marine Protected Areas' (2016) 65 Marine Policy 30-38, 30.

$74 \quad \mathrm{~K}$ Gjerde, 'Marine protected areas beyond national jurisdiction: Some practical perspectives for moving ahead' (2012) 27(2) International Journal of Marine and Coastal Law $351^{-} 373$.

75 P Drankier, 'Marine Protected Areas in Areas beyond National Jurisdiction' (2012) 27 (2) International Journal of Marine and Coastal Law 291-350. 
to ensure the more orderly and sustainable use of ocean resources and to avoid or minimise conflict between sectors. Most notable amongst these is marine spatial planning (MSP).

The concept of spatial planning is nothing new; it is a commonly adopted approach to land-use planning. However, its application in the marine context is of relatively recent origin. ${ }^{76}$ Although no agreed definition exists, MSP can generally be said to refer to 'a process of analysing and allocating parts of the three-dimensional marine spaces to specific uses to achieve ecological, economic and social objectives that are usually specified through the political process.' ${ }^{77}$ In general, MSP is seen as a 'complicated but necessary process, to establish a more rational organisation of using marine space and the user interactions in order to protect the biological diversity of the marine environment, while taking into account social and economic values.' ${ }^{78}$ It is a forward-looking, proactive planning process intended to result in a comprehensive plan or vision for a marine region that both allocates and reconciles the use of marine space on an integrated, cross-sectoral basis. ${ }^{79}$ It is widely considered to be a useful tool for ensuring the equitable and efficient utilisation of resources and for avoiding, or at least managing, conflict both between various sectors and between human uses and the marine environment. Thus, MSP can also be utilised to resolve conflicts over uses of and activities on the seabed and to promote ecosystem-based management. ${ }^{80}$

MSP builds on the concept of integrated coastal zone management (ICZM) and other non-spatial integrated approaches to deliver a more spatial approach

76 T Potts, 'Marine spatial planning and various uses and interest relating to the marine environment' in N Soininen and D Hassan (eds) Transboundary Marine Spatial Planning and International Law (Routledge, 2015) 42-59. For reviews of recent MSP practice see S Jay, W Flannery, J Vince, W Liu, JG Xue, M Matczak, J Zaucha, H Janssen, J van Tatenhove, H Toonen, A Morf, E Olsen, JL Suarez de Vivero, JCR Mateos, H Calado, J Duff and H Dean, 'International Progress in Marine Spatial Planning' (2013) Ocean Yearbook 171-212 and K Scott, 'The Evolution of Marine Spatial Planning in New Zealand: Past, Present and Possible Future' (2016) 31(54) International Journal of Marine and Coastal Law 652-689.

77 C Ehler and F Douvere, 'Marine Spatial Planning: A Step-by-Step Approach Toward Ecosystem-Based management', Intergovernmental Oceanographic Commission and Man and the Biosphere Programme, IOC Manual and Guides No 53, IOCAM Dossier No 6 (UnESCo Paris 2009), 18.

78 F Maes, 'The international legal framework for marine spatial planning' (2008) 32 Marine Policy $797-810,798$.

79 N Soininen and D Hassan, 'Marine spatial planning as an instrument of sustainable ocean governance' in N Soininen and D Hassan (eds) Transboundary Marine Spatial Planning and International Law (Routledge, 2015) 3-12, 4; CN Ehler and F Douvere, 'An international perspective on marine spatial planning initiatives' (2010) 37(3) Environments 9-20. Ehler and F Douvere, n 77; Maes, n 78808. 
which includes the zoning of marine spaces. ${ }^{81}$ Similarly, it builds on the concept of other area-based measures, in particular MPAs, which are, in effect, small-scale models of ecosystem-based marine spatial plans. ${ }^{82}$ However, it is important to distinguish between MSP and MPAS. MPAs are aimed at ensuring the protection of vulnerable marine ecosystems. MSP is aimed at ensuring the orderly and sustainable use of ocean spaces. Thus, MPAs are only one tool in the MSP tool-kit which is used to achieve more than mere area protection..$^{83}$ Of course MSP is not intended to exhaustively plan every inch of ocean space. Rather, it provides a process by which areas of strategic importance can be identified, cumulative impacts can be addressed, and conservation of ecosystem services can be maximised in an integrated, cross-sectoral management framework. The processes by which these ends are to be achieved are generally considered to include transparent and meaningful engagement and stakeholder participation, data collection, mapping and analysis of existing uses, identification of alternative use patterns, monitoring and enforcement. ${ }^{84}$ To these can be added the need to identify and/or establish the authority responsible for the planning process and the requirement of adequate financing and resources. ${ }^{85}$

At its heart, MSP seeks to ensure integration of oceans management on sectoral, spatial and temporal scales. MSP is thus a response to the traditional fragmented, incoherent and uncertain approach to oceans management. Sectoral overlaps can be identified and resolved. International, regional, national and local regulatory scales can be identified, and their application assessed and coordinated. Social, economic and ecological interests can be identified and accounted for, although competition between these various interests may be fierce and strong political mechanisms will be needed to resolve them. In this respect, it is important to remember that MSP does not do away with the need for effective (and enforceable) sectoral ecosystem-based management. The 'mere act of delineating spaces' can never be 'sufficient to achieve management objectives' ${ }^{86}$ Rather, the idea of MSP is that it complements and coordinates sectoral approaches, taking a particular area or region

\footnotetext{
$81 \quad$ Potts, $\mathrm{n} 76,43$.

82 PJS Jones, LM Lieberknecht and W Qiu, 'Marine Spatial planning in reality: Introduction to case studies and discussion of findings' (2016) Marine Policy 256-264, 262.

83 Scott, $\mathrm{n}_{76}, 656$.

84 Ehrle and Douvere, $\mathrm{n} 77$.

85 Potts, $\mathrm{n}_{76}, 44$.

86 J Duff, 'Trends on Ocean Zoning - Layers of Confusion and Approaches to Clarity' in AChircop, T McDorman and S Rolston (eds) The Future of Ocean Regime Building: Essays in Tribute to Douglas M. Johnston (Nijhoff Brill, 2009) 159-174, 162.
} 
as a whole and integrating policies and objectives across different sectors in order to achieve holistic, integrated, coherent, rational and ecologically sustainable use of marine spaces and resources. ${ }^{87}$ In this respect, MSP is said to provide the strategic context for sustainable development in the marine realm. 88

In theory, MSP appeals as a process that recognises and integrates environmental and ecological interests with socio-economic ones. ${ }^{89}$ In practice, reviews of MSP implementation in the national domain suggest that it is not necessarily delivering ecosystem-based management. ${ }^{90} \mathrm{MSP}$ is often focused on achieving specific sectoral objectives, such as the promotion of offshore wind energy, ${ }^{91}$ and on promoting 'blue growth' activities. ${ }^{92}$ Even in the Great Barrier Reef Marine Park, the quintessential 'poster child' for MSP, environmental interests are often compromised by economic ones such as terrestrial farming and port construction, with the Australian government having to fend off attempts to have the Great Barrier Reef placed on the World Heritage in Danger List. Clearly, as a tool for ecosystem-based management, MSP requires the integration of frameworks to assess ecosystem services and the implementation of precautionary and adaptive management approaches. ${ }^{93}$ This requires convincing both new and existing sectors of the advantages and opportunities that genuine integrated, collaborative and ecosystem-based approaches can offer, a difficult task even at the national level. ${ }^{94}$ In ABNJ, the effective application of MSP further requires a level of coherence and cooperation among and between global and regional agreements, institutions and national administrations that simply does not yet exist. ${ }^{95}$ As discussed in the next section, however, some developments are occurring in this regard.

$87 \quad$ P Gilliland and D Laffoley, 'Key elements and steps in the process of developing ecosystembased marine spatial planning' (2008) 32 Marine Policy $787-796$.

88 Soininen and Hassan, $\mathrm{n}$ 79, 9.

$89 \quad$ F Douvere, "The importance of marines spatial planning in advancing ecosystem-based sea use management' (2008) 32 Marine Policy $762-771$.

9o E Domínguez-Tejo, G Metternicht, E Johnston and L Hedge, 'Marine Spatial Planning advancing the Ecosystem-Based Approach to coastal zone management: A review' (2016) 72 Marine Policy $115^{-130 .}$

91 Potts, $\mathrm{n} 76,53$; Jones et al, $\mathrm{n} 82$.

92 Jones et al, n 82, 262-263; M Young, 'Building the Blue Economy: The Role of Marine Spatial Planning in Facilitating Offshore Renewable Energy Development' (2015) 30 International Journal of Marine and Coastal Law 148-173.

93 Domínguez-Tejo, n 90.

94 Potts, $\mathrm{n} 76,57$.

95 JA Ardron, K Gjerde, S Pullen and V Tilot, 'Marine spatial planning in the high seas' (2008) 32 Marine Policy 832-839. 
Regulation of ocean activities in ABNJ is characterised by high levels of governance, regulatory and substantive fragmentation. Absent a single centralised regulatory authority, a comprehensive integrated approach to ABNJ management such as that represented by MSP requires high degrees of international and inter-regime cooperation. While not as developed as in the domestic sphere, cross-sectoral initiatives are emerging which indicate possible ways forward for the integration of MSP-type management of seabed uses in ABNJ. Two examples discussed here relate to the protection of vulnerable benthic ecosystems in the North East Atlantic from the adverse effects of bottom-fishing, and the protection of undersea cables from deep seabed mining activities. These examples provide interesting studies in the possibilities, through coordinated management, of the implementation of the general principles articulated in the LOSC; the first exploring the balance between the principles of due regard, equitable and efficient use of resources and protection and preservation of the marine environment, while the second adds consideration of the principle of international communication to the mix.

\subsection{Conservation of Seabed Ecosystems vs Bottom-Fishing in the North East Atlantic}

Protection of vulnerable benthic ecosystems has its origins in the 1990s. It emerged from the recognition of the need for holistic ecosystem-based approaches to environmental protection coupled with the increasing realisation of the adverse effects of fishing activities on other parts of the marine ecosystem and on the protection of marine biodiversity.

In the North East Atlantic, two regional organisations are changed with protection of aspects of the marine environment: the ospar Commission for the Protection of the Marine Environment of the North-East Atlantic and the North-East Atlantic Fisheries Commission (NEAFC). While the two commissions cover the same geographic area, neither their membership nor their areas of application are the same. OSPAR has competence within both areas under and areas beyond national jurisdiction, while NEAFC's competence is limited to the high seas beyond national jurisdiction. In addition, their mandates, while complimentary, are completely distinct. NEAFC has competence over fisheries in $\mathrm{ABNJ}$ while OSPAR has competence in relation to the management of human activities (including those on the seabed) that impact the marine environment, including the protection and conservation of ecosystems and biodiversity in ABNJ. OSPAR's competence specifically excludes fisheries, shipping and seabed mining, although it does have a mandate to bring any such issues to the attention of the relevant international organisations. 
In 2003 the OSPAR Commission formally adopted the ecosystem approach as the basis for its management activities and adopted a strategy to establish, by 2010, an ecologically coherent network of MPAS in the OSPAR Convention area, including in those parts of the area that constitute ABNJ. ${ }^{96}$ Given their respective mandates, the only way in which OPSAR could ensure the coherence and protection of its MPAs was to enlist the support and cooperation of NEAFC. In the years that followed parallel, rather than coordinated, efforts were expended in both organisations leading to tensions, particularly on the part of NEAFC, which was concerned by what it saw as attempts by OSPAR to usurp its managerial competence. Initial efforts by OSPAR in 2002 to propose cooperation were soundly rejected by NEAFC. The prospects of a counterproductive 'turf war' were further heightened in 2004 when OSPAR, making good on its mandate to draw to the attention of NEAFC the need to protect some coral areas on the high seas from bottom fishing, suggested the start of a dialogue. NEAFC simply responded by saying that it was working on the issue. ${ }^{97}$ Eventually, NEAFC realized that OSPAR was going to move ahead with MPAS which might impinge on its regulatory area. Thus, in 2006 the NEAFC parties amended the NEAFC Convention to remove any doubts as to NEAFC's ability to apply an ecosystem approach in order to protect vulnerable marine ecosystems (VMEs) on the seafloor from the adverse impacts of bottom-trawling. ${ }^{98}$ This allowed NEAFC to adopt the first of its precautionary bottom-trawling closures. These were expanded in 2008 and 2009 to closures on the Mid-Atlantic Ridge and the Charlie Gibbs Fracture Zone. Meanwhile, in 2007, OSPAR commenced consideration of its own MPAS in ABNJ, including areas on the mid-Atlantic Ridge. In 2010 OSPAR established six high seas MPAs, the world's first 'network' of high seas MPAs, to which a seventh was added in 2012. ${ }^{99}$

Taken together, the OSPAR and NEAFC closures have been said to represent an effective network of high seas MPAs in the North East Atlantic. In truth,

96 Bremen Joint Ministerial Statement on the Ecosystem Approach to the Management of Human Activities 'Towards an Ecosystem Approach to the Management of Human Activities", 26 June 2003. https://www.ospar.org/site/assets/files/1232/jmm_annexo5_eco system_approach_statement.pdf.

97 I Kvalvik, 'Managing institutional overlap in the protection of marine ecosystems on the high seas. The case of the North east Atlantic' (2012) 56 Ocean and Coastal Management $35^{-43}$

98 See 'Status of the 1980 Convention on Future Multilateral Cooperation in North-East Atlantic Fisheries' explaining the amendments, https:/www.neafc.org/system/files/ status-of-1980_convention-03.pdf.

99 BC O'Leary, RL Brown, DE Johnson, H von Nordheim, J Ardron, T Packeiser and CM Roberts 'The first network of marine protected areas (MPAs) in the high seas: The process, the challenges and where next' (2012) 36 Marine Policy 598-605. 
neither the ecological coherence nor the efficacy of these MPAs has yet been assessed, ${ }^{100}$ and upon closer examination a less sanguine picture emerges. Analysis of the geographical coordinates establishing the NEAFC closures and the OSPAR MPAS shows that the areas only partially overlap, potentially leading to a situation where activities undertaken under the regulation of one organisation may violate the protective measures adopted by the other. Moreover, only two of the OSPAR MPAs cover both the water column and the seabed (the Milne and Charlie Gibbs South MPAs). The others pertain to areas in which either Portugal or Iceland have claims to extended continental shelves. Until these states' submissions to the Commission on the Limits of the Continental Shelf have been dealt with it is unclear who has jurisdictional competence over what. This gives rise to very difficult issues relating to the scientific validity and ecosystem coherence of these MPAs, not to mention complicated questions of co-management as between OSPAR and the coastal states. In addition, the possibility exists that contracts could be issued by the ISA for mineral exploration and exploitation in areas currently within the OSPAR MPAS, in particular in the Charlie Gibbs Fracture Zone on the Mid-Atlantic Ridge thereby completely undermining (both literally and figuratively) the OSPAR MPAs. With the ISA considering adoption of an environmental management plan for the Mid-Atlantic Ridge, the further possibility exists for inconsistent environmental protections along the physical continuum of the Mid-Atlantic Ridge ecosystem and for conflict between the OSPAR and ISA regimes.

Cooperation between OSPAR and NEAFC has now been formalized beyond their initial Memorandum of Understanding ${ }^{101}$ into the Collective Arrangement Between Competent International Organizations on Cooperation and Coordination Regarding Selected Area in Areas Beyond National Jurisdiction in the North East Atlantic, ${ }^{102}$ which provides an informal framework for dialogue and the sharing information of mutual interest within the overall context of respecting each other's mandates and legal competencies. ${ }^{103}$ However, the two main targets of the Collective Arrangement efforts, the ISA and the IMO, have, as yet, declined to join the Collective Arrangement. Admittedly, the ISA has made an effort to participate in the Collective Agreement meetings.

\footnotetext{
100 See osPar, Summary Record of the Meeting of the Biodiversity Committee, 29 February to 4 March 2016, BDC 16/9/1-E.

101 Available at https://www.ospar.org/about/international-cooperation/memoranda-of-un derstanding.

102 Established in 2014. See https://www.ospar.org/news/collective-arrangement.

103 For a history of the development of the Collective Arrangement, see, S Ásmundsson and E Corcoran, The Process of Forming a Cooperative Mechanism Between NEAFC and OSPAR, NEAFC and OSPAR (2015), https://www.ospar.org/documents?v=35111.
} 
Nevertheless, a comprehensive, cooperative mechanism for coherent, coordinated and holistic ecosystem-based management of multiple and possibly conflicting human uses of the seabed in the OSPAR MPAs is still missing.

\subsection{Submarine Cables and Deep Seabed Mining}

Another example of emerging cross-sectoral planning relates to submarine cables and deep seabed mining. ${ }^{104}$ Submarine cables are the backbone of the global economy carrying up to 98 percent of international telecommunications. This critical international infrastructure, which is almost entirely privately owned, criss-crosses the world's oceans over a total combined length of 1,576,481 kms. Cables are light weight, unprotected, and carefully laid to minimize the risk of fault or damage. Repairs to cables, particularly in $\mathrm{ABNJ}$, are expensive, time consuming and highly technical.

Traditionally the greater water depths in ABNJ have protected cables from human interference, although they have always been subject to natural threats such as earthquakes, landslide and deep currents. ${ }^{105}$ With the advent of deep seabed mining operations in $\mathrm{ABNJ}$, however, the potential exists for cable laying and mining operations to come into conflict with each other. Two areas of particular current concern are the Eastern Pacific Ocean and the Indian Ocean where cables traverse areas over which the ISA has already issued exploration permits for polymetallic nodules. ${ }^{106}$ The fear of the cable owners is that mining operations may damage the cables. The fear of the mining contractors is that cable laying and repair operations will interfere with or possibly cause damage to their mining operations. In both cases, economic losses could be substantial.

In contradistinction to seabed mining companies, whose operations and interests are the concern of the ISA, cable operators are not represented by any inter-governmental organisation, although their activities are carried out in pursuance of a number of international treaties. Rather, they are represented by the non-governmental International Cable Protection Committee (ICPC). In 2015, the ISA and the ICPC held a workshop with the purpose of identifying and addressing the issues involved in the potential risk of interference between submarine cables and deep seabed mining and finding 'practical solutions for

\footnotetext{
104 On the commercial aspects of submarine cables, see Chapter 26 in this book, L.O. Askheim 'Commercial arrangements and liability for crossing pipelines, power cables and telecommunication cables on the seabed'.

105 ISA, 'Submarine Cables and Deep Seabed Mining: Advancing Common Interests and Addressing UNClos 'Due Regard' Obligations' Technical Study No 14 (ISA, 2015), 17-19.

106 ISA, 'Submarine Cables and Deep Seabed Mining: Advancing Common Interests and Addressing UnClos 'Due Regard' Obligations', Briefing Paper 03/2105 (ISA, 2015), 3.
} 
the peaceful coexistence of both uses in' ABNJ. ${ }^{107}$ It will be recalled that the LOSC expressly authorises both activities however it equally expressly stipulates that these activities must be carried out with 'due regard' for each other (and for other users). In other words, both cable owners and mining contractors are required to exercise due regard for each other. Unfortunately, the LOSC does not define what constitutes 'due regard'. Thus, the workshop looked at practical procedures to reduce risks and avoid disputes between the two constituencies. Key to these was an understanding that, at the very least, 'due regard' requires first notice, either actual or constructive, and then consultation between the cable owners and contractors engaged in competing activities. ${ }^{108}$ It was agreed, among other things, that the ISA and the ICPC should cooperate as points of contact, facilitators and information disseminators to ensure that their respective audiences would be able to identify solutions to cable location should exploitation occur in the future. It was further suggested that mapping of exploration areas under contract with the ISA and eventual cable locations would be useful, as would a joint code of conduct or the unilateral adoption by both organisations of appropriate recommendatory guidance on how to avoid conflicts with each other's operations. ${ }^{109}$ Whether such recommendations will be adopted remains to be seen. Suffice it to say here that the need to reduce conflicts between seabed activities in ABNJ has, at least, been identified, and some concrete practical steps have been suggested as to how best to go about it.

What these two examples show is an increasing awareness of the need to cooperate across sectors in order to avoid, minimise or manage conflict, even at the international level. This is being achieved, to an as yet minor extent, through memoranda of understanding and other agreements or arrangements providing for cooperative activities such as joint workshops, work programs, and meetings, and participation in each other's meetings as observers. The success of these ventures remains, however, dependent on some common understanding of their potential benefits, such as certainty, prevention of duplication, increase in efficiency in achieving agreed goals and targets, and on the further development of significantly more, more complex, and more constructive processes for cooperation. ${ }^{110}$

\footnotetext{
107 ISA, n 104, 5 .

108 Ibid, 27.

109 Ibid, 33-34.

110 JA Ardron, R Rayfuse, K Gjerde, R Warner, "The sustainable use and conservation of biodiversity in ABNJ: What can be achieved using existing international agreements?" (2014) 49 Marine Policy $98-108$.
} 


\section{Conclusion}

This chapter has provided an overview of the key environmental approaches and tools that are being developed in order to reduce, minimise and avoid conflict between different uses and users of the seabed. It will be immediately apparent that a plethora of such approaches and tools exist, although not all are necessarily focused on precautionary and ecosystem-based management. In both areas under and areas beyond national jurisdiction certain key features of sound environmental management exist. First, it is necessary to know and understand what each sector is doing. Then the impacts that the activities of each sector can have or are likely to have on another sector must be assessed. Finally, cross-sectoral cooperation, aimed at ensuring each sector is interfered with only to the extent necessary and in a manner that does not compromise ecosystem integrity, is needed. This is not an easy task. However, the future orderly, peaceful and environmentally sustainable development and use of the seabed depends on it. 